\title{
Stability of Water-Soluble Chlorophyll Protein (WSCP) Depends on Phytyl Conformation
}

Daniel M. Palm§, Alessandro Agostini ${ }^{\ddagger} \#^{*}$, Anne-Christin Pohland ${ }^{\ddagger}$, Mara Werwie ${ }^{\ddagger}$, Elmar Jaenicke ${ }^{\dagger}$, and Harald Paulsen ${ }^{\ddagger *}$

${ }^{\ddagger}$ Institute of Molecular Physiology, Johannes Gutenberg-University, Johannes-von-Müller-Weg 6, 55128 Mainz, Germany

${ }^{\dagger}$ Institute of Molecular Physiology, Johannes Gutenberg-University, Jakob-Welder-Weg 26, 55128 Mainz, Germany

\section{Corresponding Authors}

*H.P. E-mail: paulsen@uni-mainz.de

*A.A. E-mail: alessandro.agostini.1@unipd.it

\section{Present Address}

\#Department of Chemical Sciences, University of Padova, via Marzolo 1, 35131 Padova, Italy

Table S1: Mutations in the LCPS motif of Lv- wt. Mutated amino acids are highlighted in bold. Numbers indicate the position of the amino acids in the polypeptide sequence. Conserved amino acids (W and S) flanking the LCPS motif are shown.

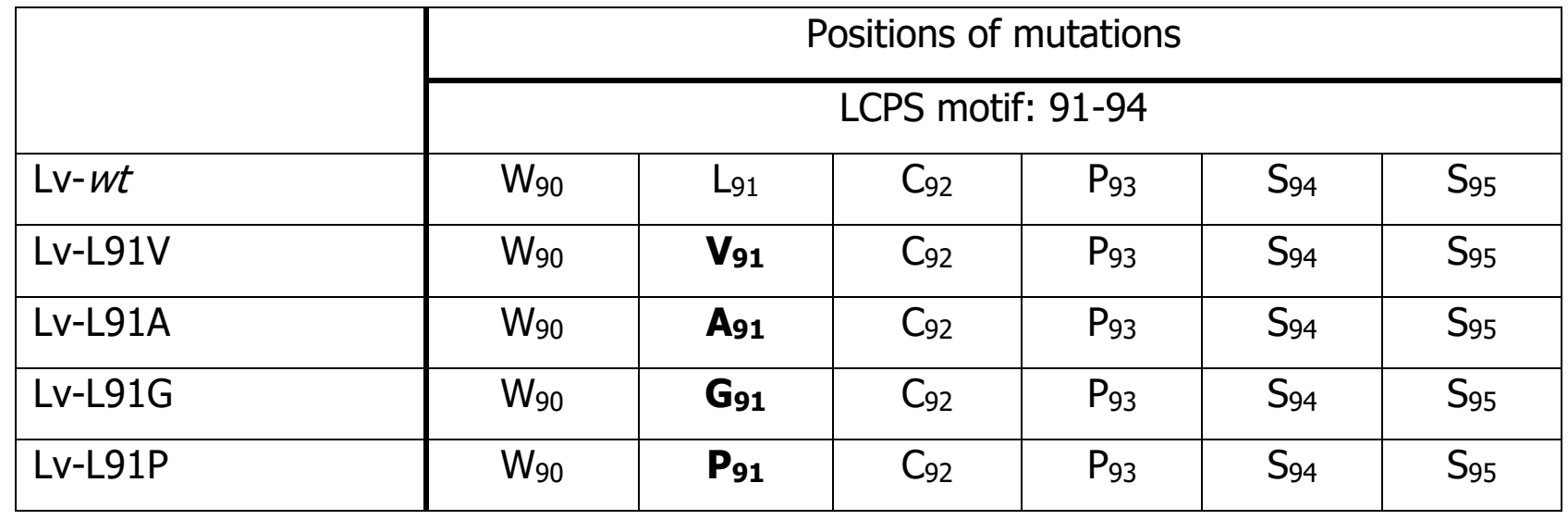




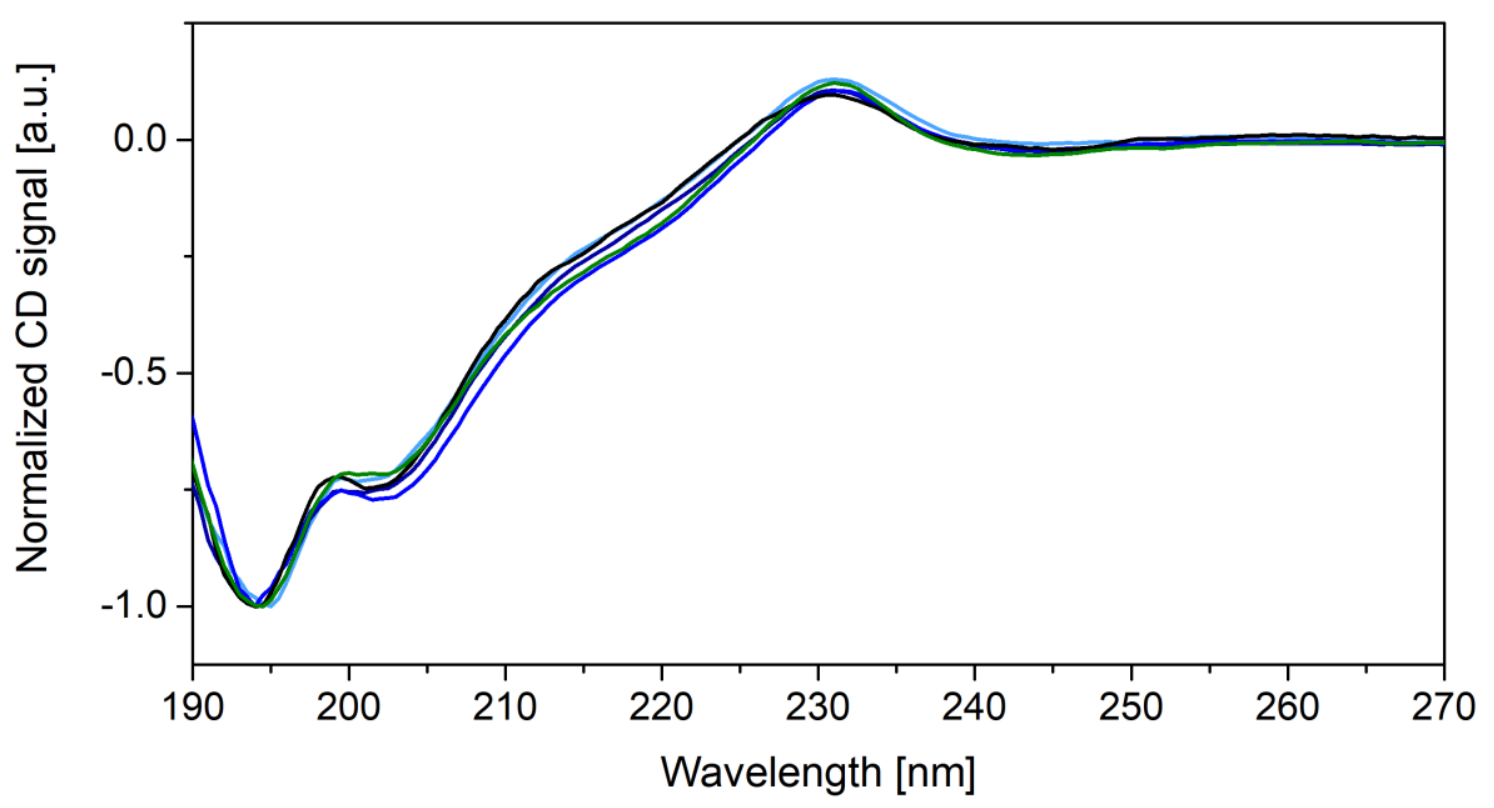

Figure S1: UV-CD spectra of Lv-wt (black), Lv-L91V (dark blue), Lv-L91A (blue), L91G (light blue), Lv-L91P (dark green). The spectra were normalized to -1 at the minima.
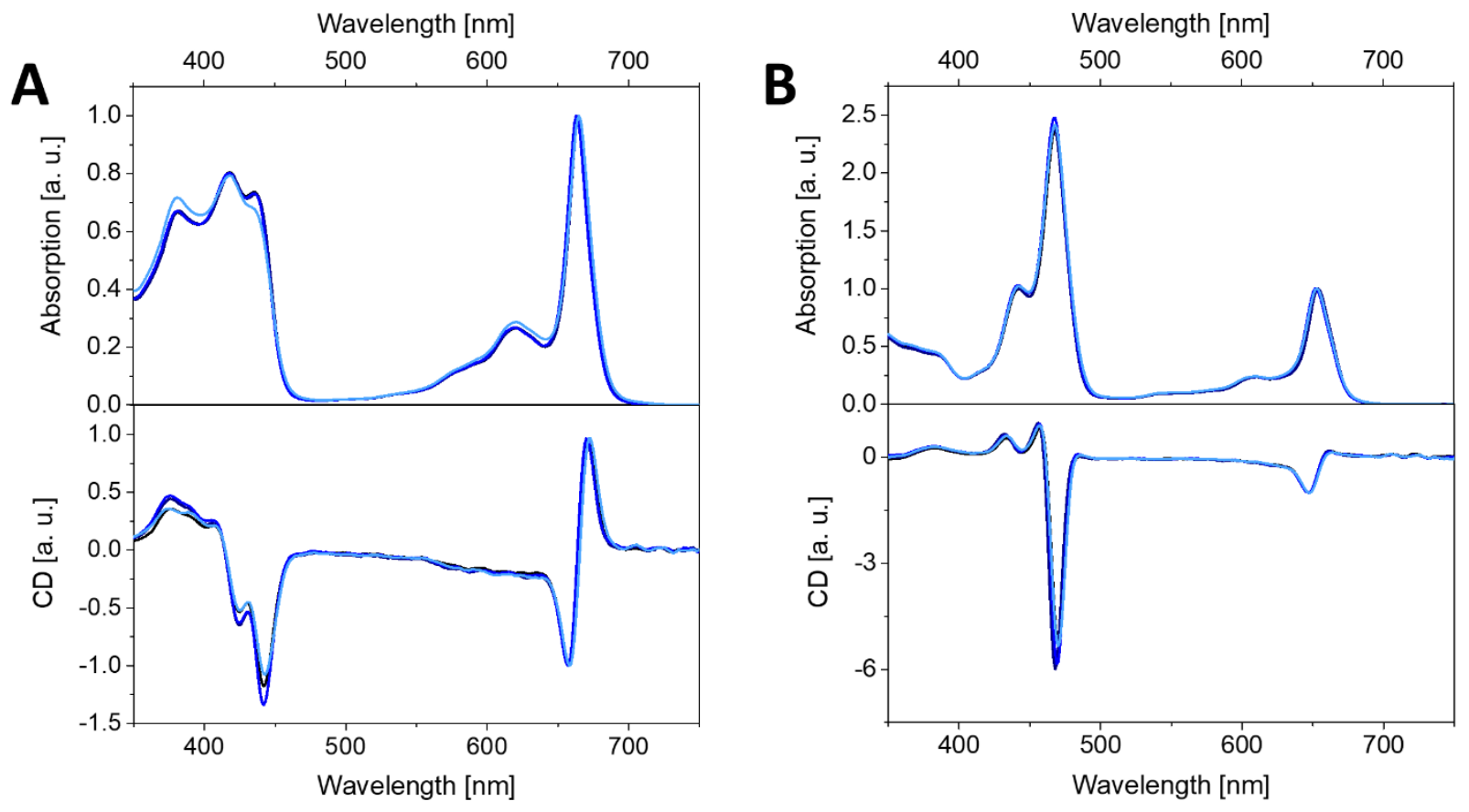

Figure S2: Spectroscopic comparison of Lv-wt (black), Lv-L91V (dark blue), Lv-L91A (blue), Lv-L91G (light blue). Absorption (top) and Vis-CD (bottom) spectra after reconstitution with Chl $a$ and after reconstitution with $\mathrm{Chl} b$ (A and $\mathrm{B}$, respectively). Absorption spectra were normalized to 1 at the $\mathrm{Q}_{\mathrm{y}}$ maxima. Vis-CD spectra were normalized to -1 at the $Q_{y}$ minima. 

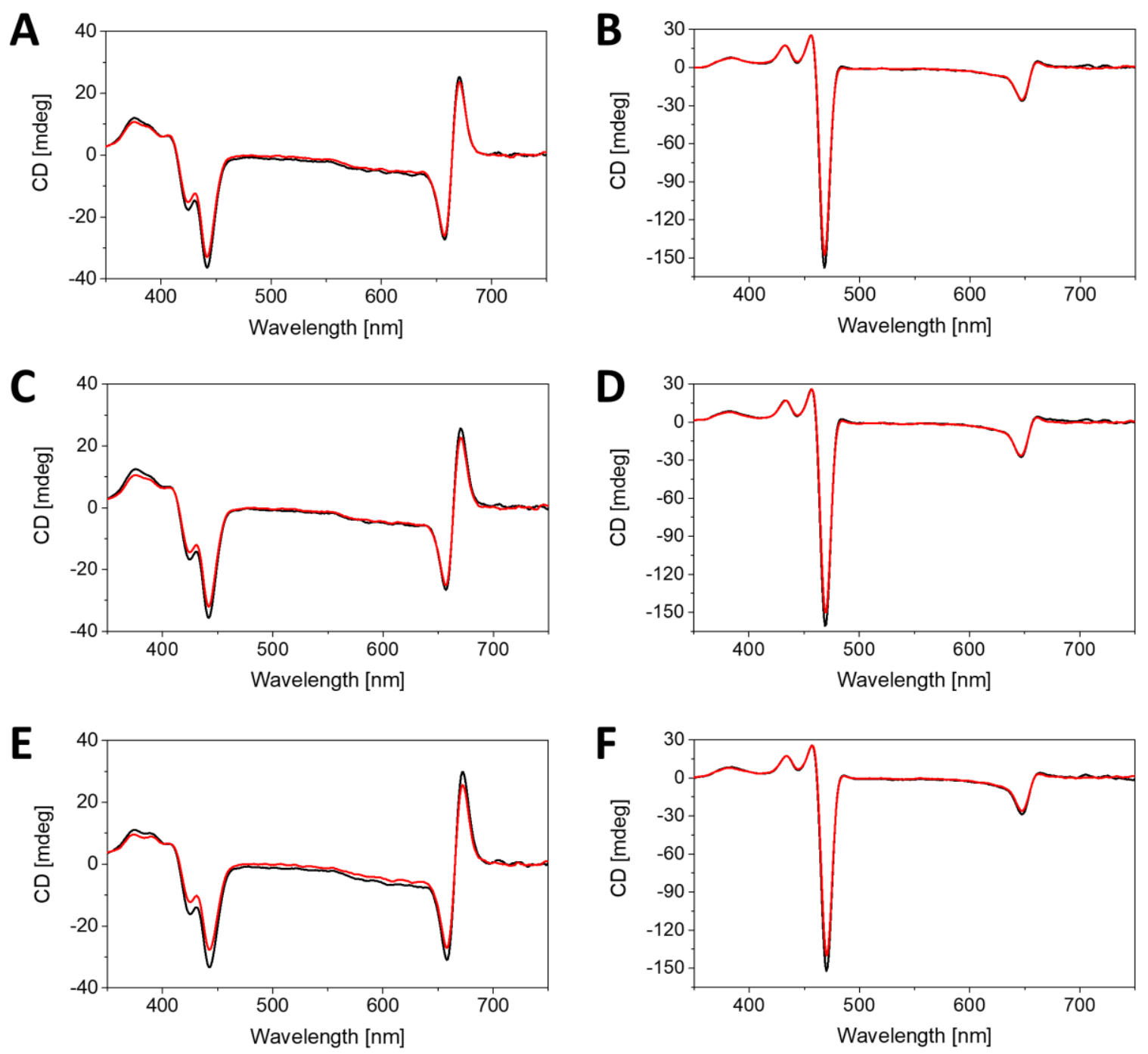

Figure S3: Heat stability of Lv-L91V reconstituted with $\mathrm{Chl} a(\mathrm{~A})$ and $\mathrm{Chl} b(\mathrm{~B})$; Lv-L91A reconstituted with $\mathrm{Chl} a(\mathrm{C})$ and $\mathrm{Chl} b(\mathrm{D})$; and $\mathrm{Lv}$-L91G reconstituted with $\mathrm{Chl} a(\mathrm{E})$ and $\mathrm{Chl} b(\mathrm{~F})$. Vis-CD spectra were recorded before (black) and after (red) a 5 min boiling treatment. The spectra were normalized to the maximum of their corresponding $\mathrm{Chl} \mathrm{Q}_{\mathrm{y}}$ absorption band. 